\title{
DESCONSTRUINDO A LÓGICA DA ESCOLA SEM PARTIDO: glosas críticas
}

\author{
Jorge Fernando Hermida ${ }^{1}$ \\ Jailton de Souza Lira²
}

\begin{abstract}
RESUMO
Este ensaio versa sobre os fundamentos políticos e pedagógicos da proposta do movimento Escola sem Partido (ESP). Apresenta uma série de glosas críticas sobre um dos temas educacionais mais relevantes dos últimos tempos, as quais representam o ponto de vista crítico dos autores, mas também de amplos setores educacionais e sociais, defensores da escola pública e da democracia. Ancorado nos fundamentos teóricos e metodológicos da Pedagogia Histórico-crítica e do materialismo histórico e dialético, o ensaio conclui que o Escola sem Partido se constitui em um movimento autoritário, articulado com o movimento fascista internacional e com os setores políticos e econômicos mais reacionários da sociedade. Suas propostas representam o violento esforço do sistema capitalista em manter o seu processo de acumulação e concentração da riqueza, ainda que precise utilizar recursos que minam o Estado democrático de Direito liberal e as limitadas conquistas decorrentes da ampliação dos espaços de democratização formal pós Constituição de 1988.
\end{abstract}

Palavras-chave: Escola sem Partido. Democracia liberal. Fundamentos da educação.

\section{DECONSTRUCTING THE LOGIC OF THE SCHOOL WITHOUT A PARTY:}

\section{critical gloses}

\begin{abstract}
This essay deals with the political and pedagogical foundations of the proposal of the movement School without Party (ESP). A series of glosses is presented on one of

1 Uruguaio, naturalizado brasileiro. Doutorado em Educação, pela Universidade Estadual de Campinas (UNICAMP). Professor Titular da Universidade Federal da Paraíba (UFPB) e dos Programas de Pós-graduação em Educação (PPGE) e do Mestrado Profissional em Gestão em Organizações Aprendentes (MPGOA), ambos da UFPB. Líder do Grupo de Estudos e Pesquisas "Educação, Políticas Públicas e Mundo do Trabalho - membro do HISTEDBR Nacional". ORCID: https://orcid.org/0000-0003-1963-463. Contato: jorgefernandohermida@yahoo.com.br

${ }^{2}$ Doutorado em Educação, pela Universidade Federal da Paraíba (UFPB). Professor Adjunto II da Universidade Federal de Alagoas (UFAL) e do Programa de Pós-graduação em Educação (PPGE) da UFAL. Presidente da Associação de Docentes da Universidade Federal de Alagoas (ADUFAL). Vice-Líder do Grupo de Estudos e Pesquisas "Educação, Políticas Públicas e Mundo do Trabalho - membro do HISTEDBR Nacional". ORCID: https://orcid.org/0000-0002-3534-0553. Contato: jailton.lira@cedu.ufal.br
\end{abstract}


the most relevant educational themes of recent times, which represent the critical point of view of the authors, but also of broad educational and social sectors, defenders of the public school and democracy. Anchored in the theoretical and methodological foundations of Historical-Critical Pedagogy and historical and dialectical materialism, the essay concludes the following: Escola sem Partido is an authoritarian movement, which is articulated with the international fascist movement and with the most reactionary political and economic sectors of society. His proposals represent the violent effort of the capital system to maintain its process of accumulation and concentration of wealth, even though it needs to use resources that undermine the democratic state under liberal law and the limited achievements made possible by the expansion of the spaces of formal democratization post 1988 Constitution.

Keywords: School without Party. Liberal democracy. Fundamentals of education.

\section{DECONSTRUYENDO LA LÓGICA DE LA ESCUELA SIN PARTIDO: glosas críticas}

\section{RESUMEN}

Este ensayo aborda los fundamentos políticos y pedagógicos de la propuesta del movimiento Escuela sin Partido (ESP). Se presenta una serie de glosas sobre uno de los temas educativos más relevantes de los últimos tiempos, que representan el punto de vista crítico de los autores, pero también de amplios sectores educativos y sociales, defensores de la escuela pública y la democracia. Anclado en los fundamentos teóricos y metodológicos de la Pedagogía Histórico-Crítica y el materialismo histórico y dialéctico, el ensayo concluye lo siguiente: Escuela sin Partido constituye un movimiento autoritario, articulado con el movimiento fascista internacional y con los sectores políticos y económicos más reaccionarios de la sociedad. Sus propuestas representan el esfuerzo violento del sistema capitalista por mantener su proceso de acumulación y concentración de riqueza, mismo que sea necesario utilizar recursos que atentan contra el Estado democrático de derecho liberal y los limitados logros que posibilitó la expansión de los espacios de democratización formales, posteriores a la Constitución de 1988.

Palabras clave: Escuela sin Partido. Democracia liberal. Fundamentos de la educación.

\section{INTRODUÇÃO}

Es mucha la podredumbre para arrojar al fondo del mar en el caminho de la reconstrucción de América Latina. Los despojados, los humillados, los malditos tienen, ellos si, em sus manos, la tarea. La causa nacional latino-americana es, ante todo, una causa social: para que América Latina pueda nacer de nuevo, habrá que empezar por derribar a sus dueños, país por país. Se abren tempos de rebelión y de cambio. Hay quienes creen que el destino descansa en las rodillas de los dioses, pero la verdade es que trabaja, como un desafío candente, sobre las consciencias de los hombres.

(Las venas abiertas de América Latina. EDUARDO GALEANO). 
Este ensaio apresenta nosso ponto de vista a respeito de um dos temas educacionais mais relevantes dos últimos tempos: a proposta conservadora, reacionária e protofascista do movimento Escola sem Partido (ESP). Após termos pesquisado e problematizado sobre o assunto em dois artigos publicados, um em 2017 (O Programa Escola Livre em Alagoas, a crise de acumulação do capital e o fortalecimento da direita política brasileira $)^{3}$ e o outro em 2020 (Quando fundamentalismo religioso e mercado se encontram: as bases históricas, econômicas e políticas da escola sem partido), ${ }^{4}$ desta vez nos propomos a defender uma série de glosas críticas, 5 que representam o ponto de vista crítico de amplos setores educacionais e sociais, defensores da escola pública e da democracia, na tentativa de contribuir criticamente para a compreensão de um tema complexo e cheio de armadilhas. 6

Ancorados nos fundamentos teóricos e metodológicos da Pedagogia Histórico-crítica e do materialismo histórico e dialético, consideramos este tema relevante, não pelo conteúdo e contribuições da proposta em si ou por ela ser significativa para a superação das históricas mazelas educacionais que caracterizam a educação brasileira como um todo, mas, ao contrário, evidenciar os perigos que esta encena.

Do ponto de vista histórico, o movimento surgiv em 2004, tendo como idealizador o procurador do Estado de São Paulo Miguel Nagib. Desde suas origens, o movimento afirma ser apartidário e contrário à doutrinação ideológica que, na opinião de seus seguidores, acontece nas salas de aula brasileiras. Estas propostas ganharam visibilidade após o encontro do propositor Miguel Nagib com membros da família Bolsonaro em 2014, no Rio

\footnotetext{
3 Disponível em: <https://doi.org/10.24065/2237-9460.2018v8n1ID393>

${ }^{4}$ Disponível em: <https://doi.org/10.18593/r.v45i0.23216>

5 O uso do termo procura incorporar o teor crítico que caracterizaram os escritos marxianos, em especial o das Glosas críticas marginais ao artigo "O rei da Prússia e a reforma social. De um prussiano", de 1844. Nessa ocasião, Karl Marx fez no artigo uma arrazoada crítica às visões hegelianas de Filosofia, de Política e de Estado.

6 Dentre os intelectuais que mais tem contribuído com ideias para a compreensão da complexa realidade educacional brasileira temos a Gaudêncio Frigotto. O autor tem se debruçado na temática, com aportes críticos que foram publicados em livros. Dentre as contribuições mais significativas, destacamos: Educação democrática: antídoto ao Escola sem Partido (FRIGOTTO, G.; PENNA, F.; QUEIROZ, F., 2018) e Escola "sem" Partido. Esfinge que ameaça a educação e a sociedade brasileira (FRIGOTTO, 2017).
} 
de Janeiro. O encontro fortaleceu o movimento, pois a família assumiu para si a tarefa de apresentar na Câmara de Vereadores (com o vereador Carlos Bolsonaro) e na Assembleia do Governo do Estado (com o deputado estadual Flávio Bolsonaro) propostas pontuais de projetos de lei, que endossam as proposituras originais do Escola sem Partido.

A partir de então, gradualmente $O$ movimento foi ganhando visibilidade e simpatizantes em todos os segmentos da sociedade. $O$ efeito dominó fez com que projetos do mesmo teor se multiplicassem em todos os Estados, no Distrito Federal e no Congresso Nacional. O combate do movimento defensor da família tradicional contra a "ideologia de gênero", a "doutrinação ideológica" e a favor da "caça aos professores comunistas" ampliou-se para todos os setores educacionais, marcando forte presença nas instituições educativas, desde a Educação Infantil até o Ensino Superior (HERMIDA e LIRA, 2017; HERMIDA e LIRA, 2020).

Quando o cenário político sinalizou uma conjuntura amplamente favorável para multiplicar e aprovar suas propostas, no ano de 2019 , surpreendentemente o criador do movimento (Miguel Nagib) decidiu encerrar oficialmente suas atividades. Dentre os motivos que o levaram a essa decisão, estavam a falta de apoio da Presidência da República (de Jair Messias Bolsonaro, contraditoriamente) e principalmente dificuldades financeiras (CARTA CAPITAL, 2019; HERMIDA e LIRA, 2020). .7 No entanto, no comando do Ministério da Educação (MEC) a partir de abril de 2019, o seu titular Abraham Weintraub e outros representantes do governo pertencentes à "ala ideológica" mantiveram estreita aproximação com o movimento.

Weintraub foi um dos fervorosos defensores da presença do Escola sem Partido nas universidades. No começo de sua gestão, ele chegou a pedir que os estudantes filmassem os professores em sala de aula, pois, na opinião dele, essa ação iria contribuir para uma "revolução cultural" na educação.

\footnotetext{
7 Nas mídias sociais (Facebook), o movimento declarou o seguinte: "Por absoluta falta de apoio, suspenderemos nossas atividades neste perfil a partir de $1^{\circ}$ de agosto. Daí pra frente, denúncias, pedidos de socorro e orientação deverão ser dirigidos ao MEC, secretarias de educação, Ministério Público e políticos que se elegeram com a bandeira do ESP"

(<https://www.facebook.com/escolasempartidooficial/posts/1356649304486057> Acesso em: 04 de setembro de 2020).
} 
O termo revolução cultural continua sendo um dos mais usados pelo deputado federal Eduardo Bolsonaro e seu clã cada vez que se referem a assuntos educacionais.

Após Abraham Weintraub8 sofrer indiciamento por uma série de ações criminosas vinculadas a fake news - por comparar ações de busca e apreensão da Polícia Federal sobre fake news (contra 29 empresários, políticos e blogueiros simpatizantes do governo Bolsonaro) com o episódio da Noite dos Cristais nazista, ${ }^{9}$ falta de decoro (por atacar os poderes constituídos democraticamente e ofender os ministros do Supremo Tribunal Federal - STF - com palavras de baixo calão) e racismo (por ter publicado comentários depreciativos contra o maior sócio comercial do país, a República Popular da China), ele se demitiu do cargo e saiu do país de maneira controversa. Antes destes fatos, Weintraub indicou dez pessoas para compor o Conselho Nacional de Educação, nomeadas posteriormente. Dessas pessoas, oito se manifestaram fervorosos simpatizantes do movimento Escola sem Partido.

\begin{abstract}
8 A gestão de Abraham Weintraub (abril de 2019 a junho de 2020), ficou conhecida pelas controvérsias que a caracterizaram. Weintraub demonstrou incompetência e falta de conhecimento na frente do ministério. Dentre os "desserviços" prestados por Weintraub, destacam-se: o contingenciamento dos recursos financeiros das Universidades Federais; corte de verbas em todos os níveis de ensino; o Programa Escola Para Todos, que procurava promover economia na hora de comprar materiais escolares; o fracasso na gestão do ENEN por ter se detectado troca de 6 mil gabaritos que acarretaram erros na correção das provas. No ano de 2019, a CAPES perdeu um terço do seu financiamento - passou de R\$ 4,25 bi para $R \$ 2.84$ bilhões - e com isso $8 \%$ das bolsas foram cortadas, sendo que nas Ciências Humanas o corte atingiu $17 \%$. Ele foi o criador do programa FUTURE-SE para as universidades públicas federais; chamou aos professores universitários de "zebras gordas"; e implementou o projeto piloto do Programa Nacional das Escolas Cívico-Militares, que está presente em 26 cidades de 18 estados brasileiros. Weintraub também aprovou uma Medida Provisória (MP) para permitir que o ministro da educação possa nomear diretamente, durante a pandemia do coronavírus, a reitores pró-tempore de 15 universidades federais e 4 institutos federais. A MP 979 foi publicada no Diário Oficial da União pelo Presidente Jair Messias Bolsonaro em 10/06/2020. O próprio Presidente revogou a MP dois dias depois (12/06/2020), horas depois de o Presidente do Senado, David Alcolumbre (DEM-AP), ter devolvido o texto ao Poder Executivo, por ele violar os princípios constitucionais da autonomia e da gestão democrática das universidades.

9 Trata-se de um episódio histórico ocorrido no ano de 1938, quando os judeus começam a ser perseguidos na Alemanha e amplos territórios serem anexados pelo nazismo comandado por Adolf Hitler. Comércios foram depredados, sinagogas e instituições judaicas queimadas e muitos judeus foram violentados fisicamente e mortos. No 28/05/2020, Abraham Weintraub escreveu na sua conta de Twitter: "Hoje foi o dia da infâmia, VERGONHA NACIONAL, e será lembrado como a Noite dos Cristais brasileira. Profanaram nossos lares e estão nos sufocando. Sabem o que a grande imprensa oligarca/socialista dirá? SIEG HEIL!"
\end{abstract}

Revista Exitus, Santarém/PA, Vol. 11, p. 01 - 25, e020137, 2021. 
Para ocupar o cargo vago no MEC após a saída de Weintraub, Bolsonaro nomeou o advogado Milton Ribeiro. Ex-Reitor das Faculdades Mackenzie e pastor da Igreja Presbiteriana de Santos (SP), Ribeiro tornou-se o quarto ministro da Educação a ser indicado, substituindo Carlos Alberto Dacotelli, demitido mesmo antes de ter tomado posse no lugar de Weintraub por ter falsificado seu próprio currículo. Por estes motivos, em suas primeiras declarações Ribeiro fez questão de deixar claro que ele era Doutor em Educação pela Universidade de São Paulo (USP). Com a sua nomeação, a "ala ideológica" do governo Bolsonaro continuou prevalecendo, uma vez que o novo ministro também é simpatizante das propostas do movimento Escola sem Partido (REVISTA VEJA, 2020; UOL, 2020).

A recomendação da Escola sem Partido para a educação nacional representa uma proposição pouco objetiva e de alto teor subjetivista, que descaracteriza as finalidades do ato de educar (independentemente de sua perspectiva pedagógica) - reduzindo-o a um simples ensino instrumental. Ancorado numa pretensa neutralidade, procura submeter todas as ações educativas a serviço daqueles que detêm o status quo na sociedade capitalista - a burguesia cosmopolita, a burguesia nacional (financeira, agrária e industrial) e o grande capital internacional.

Concomitante a isto, temos uma forte campanha de desmoralização dos trabalhadores da educação pública (professores), pois, na opinião deste movimento, o trabalho docente estaria descontruindo os modelos tradicionais de família e sociedade, influenciando na sexualidade e doutrinando ideologicamente as crianças (que eles enquadram em um ilusório marxismo cultural). Como na ótica desses grupos direitistas o trabalho docente estaria se desviando de suas verdadeiras finalidades educativas, o movimento da Escola sem Partido e seus projetos de lei pontualmente elaborados e apresentados nos cenários políticos municipais, estaduais e nacional, almejam criminalizar as atividades do magistério, impedindo, desta forma, as ações educativas reflexivas, críticas e socialmente contextualizadas sobre os principais acontecimentos políticos e sociais contemporâneos. 
Diante do exposto, este ensaio visa desconstruir, crítica e academicamente, a lógica das propostas do movimento Escola sem Partido. Para atingir este objetivo, trazemos uma série de glosas críticas, elaboradas a partir de conhecimentos e pesquisas advindos da ciência. Em tempos de terraplanismo, 10 negacionismo ${ }^{11}$ e obscurantismo medieval, explicitar a perspectiva da nossa abordagem é pertinente e extremamente necessária. As glosas críticas foram construídas com o intuito de contribuir para o debate de um dos mais relevantes temas dos últimos tempos.

Após a exposição das glosas críticas, o artigo se encerra com a apresentação das Considerações Finais.

\section{GLOSAS CRÍTICAS CONTRA A ESCOLA SEM PARTIDO}

\section{Glosa crítica. Qualquer tentativa de compreensão lógica da Escola sem}

Partido precisa remeter-se à emergência da pós-modernidade e seu critério gnosiológico, a pós-verdade.

Nadando na contracorrente das ricas e vastas tradições seculares humanistas - nas quais a razão, a ciência e o saber objetivo e historicamente situado orientam a construção de diversos paradigmas que busca compreender e apreender o real, o movimento Escola sem Partido se insere na perspectiva da rejeição das determinações históricas e ontológicas, sacralizando e invertendo o significado dos escritos religiosos e textos bíblicos, e valorizando interpretações subjetivas, descontextualizadas e pouco fundamentadas dos fatos sociais. Apelando a uma linguagem próxima do senso comum, intenciona reduzir a compreensão de questões complexas a falsas alternativas e dicotomias.

\footnotetext{
10 Trata-se de um termo anticientífico e negacionista que defende a ideia de que a terra é plana. O terraplanismo se fundamenta em algumas passagens bíblicas e dados sem comprovação científica. Mesmo sem fundamento científico, o movimento terraplanista tem conquistado adeptos - pressupõe-se que $7 \%$ dos brasileiros acreditam nessa teoria. Prova disso foi a Convenção Nacional da Terra Plana, ocorrida na cidade de São Paulo em 2019. Tanto o terraplanismo quanto o negacionismo fazem parte do léxico da pós-verdade.

11 Trata-se de um movimento político e cultural que visa a negação de fatos e acontecimentos históricos, mas também de evidências científicas. Sua retórica incentiva a disseminação da ignorância a fim de camuflar os interesses daqueles que sustentam esse tipo de discurso.
} 
Na linha do discurso pós-moderno, a opção retórica do Escola sem Partido visa construir uma outra ontologia e formas de pensar o real. No dizer de Evangelista (1997, p. 23) - fazendo referência à retórica da pós-verdade -, trata-se de uma "vontade panúrgica de poder" que, onipresente e disseminada em todos os poros da vida social, busca instituir poderes microfísicos para assim poder questionar e resistir à ordem instaurada. Pois,

\begin{abstract}
O poder, assim hipostasiado, constituir-se-á na dimensão ontológica fundamental e perderá qualquer determinação histórica, não havendo detentores nem objetivos específicos do poder, nem que servissem ao poder. As relações de poder serão completamente reversíveis e indeterminadas na história. Enfim, é nesse quadro que o "discurso" constitui os sujeitos político-sociais no exercício "microfísico" do poder e na sua resistência igualmente "microfísica ou capilar" (EVANGELISTA, 1997, p. 23).
\end{abstract}

Ainda que pareça contraditório, o modo como os integrantes do Escola sem Partido lidam com a pós-verdade denota uma aplicação utilitária das suas teses. Por exemplo, as armas da crítica são violentamente atacadas quando desenvolvem julgamentos ao modelo de sociedade consumista e exploradora imposto pelo capital, mas habilmente valorizadas quando o tema é duvidar dos avanços e conquistas sociais advindos dos governos anteriores, que se orientavam por sentidos ideológicos e políticos distintos.

A perspectiva da pós-verdade também procura desautorizar as fundamentações e avanços advindos da ciência, em oposição ao interesse do pensamento irracional e dogmático oriundo do fundamentalismo religioso cristão. É possível evidenciar uma relação direta entre os fundamentos do movimento, com a defesa do livre mercado e ideais religiosos das igrejas neopentecostais (evangélicas) e da Renovação Carismática (católicas).

\title{
$2^{a}$. Glosa crítica. A Escola sem Partido faz parte de um movimento político de extrema direita, contrário aos fundamentos da democracia liberal e favorável ao autoritarismo.
}


As concepções de sociedade e de mundo do Escola sem Partido são opostas aos valores democráticos universais, à pluralidade de ideias e ao respeito à diversidade social, étnica e cultural que caracterizam não só o Brasil, mas também muitos países em pleno século XXI. Seus idealizadores acreditam que as sociedades deveriam ser regidas por normas autoritárias, moralistas, patriarcais e religiosas, a despeito dos avanços civilizatórios havidos quando da consolidação das democracias liberais, que se tornaram predominantes nos países capitalistas ocidentais nos últimos 40 anos (CASTELLS, 2018; HERMIDA e LIRA, 2020).

Trata-se de um movimento político vinculado à extrema direita, que tem como propósito desconstruir os fundamentos da democracia liberal e implementar um modelo de organização societária de viés autoritário. Sem pretender desconsiderar os valores negativos impostos pela sociedade burguesa e pela ação predatória do sistema capitalista (pois se trata de um sistema completamente autodestrutivo e excludente), é forçoso admitir que a democracia liberal representou e - continua representando - um avanço civilizatório importante a respeito dos preceitos hegemônicos do mundo após a grande crise econômica da década de 1970 (CASTELLS, 2018; LEVITSKY e ZIBLATT, 2018; HERMIDA e LIRA, 2017 e 2020). A democracia liberal capitalista se consolida com o fim das ditaduras militares latino-americanas, a independência de muitos países africanos e o desaparecimento da União de Repúblicas Socialistas Soviéticas (URSS). "Segundo o Polity Project (projeto que classifica o regime político dos países ao longo do tempo), em 1985 havia 42 democracias, onde moravam 20\% da população mundial. Em 2015, o número saltou para 103, com 56\% da população mundial" (NICOLAU, 2018, p. 07-08).

Sobre o difícil momento em que vivem os Estados democráticos liberais e as diferentes estratégias utilizadas para sua derrubada, Levitsky e Ziblatt (2018, p. 15) fazem a seguinte afirmação:

Porém, há outra maneira de arruinar uma democracia. É menos dramática, mas igualmente destrutiva. Democracias podem morrer nas mãos de generais, mas de líderes eleitos - presidentes ou primeiros-ministros que subvertem o próprio processo que os levou ao 
poder. Alguns desses líderes desmantelam a democracia rapidamente, como fez Hitler na sequência do incêndio do Reichstag em 1933 na Alemanha. Com mais frequência, porém, as democracias decaem aos poucos, em etapas que mal chegam a ser visíveis.

O teor das considerações realizadas por Levitsky e Ziblatt (2018), sobre o passado na Alemanha (1933) nos remetem forçosamente ao presente do Brasil (2021), observando o movimento que vem sendo articulado pelo Presidente Bolsonaro com os setores mais reacionários, retrógrados e fascistas da sociedade brasileira (os militares palacianos, empresários e movimentos protofascistas como "Os 300 de Brasília", que flertam com o autoritarismo). Também as palavras de Karl Marx são plenas de sabedoria, quando em $\bigcirc 18$ de Brumário de Luís Bonaparte (2011), o filósofo alemão escreveu de maneira contundente:

Em algumas passagens de suas obras, Hegel comenta que todos os grandes fatos de todos os grandes personagens da história mundial são encenados, por assim dizer, por duas vezes. Ele se esqueceu de acrescentar: a primeira vez como tragédia, a segunda como farsa (MARX, 2011, p. 25).

Neste sentido, consideramos o Golpe de 2016 uma caricatura farsesca do golpe de 1964 que instaurou o regime militar no país, que contou com o decisivo apoio dos conspiradores civis, do empresariado nacional e dos segmentos privados associados aos interesses estrangeiros.

\section{$3^{a}$. Glosa crítica. Com a falência do Estado capitalista, movimentos políticos} conservadores de extrema direita conseguem se erguer como sendo os autênticos representantes antiestablishment do sistema.

Não é de hoje que vários referentes teóricos marxistas nos alertam do fenecimento do Estado capitalista, do colapso da ilusão liberal-democrática e da ascensão de novas formas de dominação do imperialismo norteamericano. Dentre eles, os estudos e pesquisas de István Mészáros sobre a falência do Estado (failing state) ocupam um lugar preponderante:

Sob as condições do aprofundamento da crise estrutural do sistema do capital, os problemas do Estado tornam-se, inevitavelmente, cada vez maiores. Pois, na forma há muito estabelecida do processo de tomada de decisão política global, o Estado deveria 
proporcionar a solução para os vários problemas que obscurecem nosso horizonte, mas não consegue fazê-lo. Pelo contrário, tentativas de medidas corretivas de Estado - desde intervenções militares perigosas para enfrentar colapsos financeiros graves em uma escala monumental, incluindo as operações de resgate do capitalismo privado realizado pela sempre crescente dívida pública da ordem dos trilhões de dólares - parecem agravar os problemas, apesar das vãs garantias em contrário (MÉSZÁROS, 2015, p. 15).

Para o autor, o verdadeiro desafio histórico seria a superação dos antagonismos estruturantes, "...entrincheirados nas células constitutivas da ordem social do capital...", responsáveis pela atual situação de crise do Estado no capitalismo contemporâneo (MÉSZÁROS, 2015, p. 22), sendo necessário superar $\bigcirc$ impasse pautando $\circ$ problema da igualdade substantiva na agenda histórica da agitação revolucionária. Trata-se de uma difícil tarefa, tendo em vista o que vem acontecendo na sociedade brasileira.

É surpreendente a capacidade que os membros dos movimentos conservadores de ultradireita têm para distorcer a realidade, a ponto desses movimentos e partidos se tornarem atualmente nos autênticos representantes antiestablishment do sistema... numa democracia liberal capitalista e periférica! Mesmo que a sua militância seja a favor do status quo da ordem social capitalista, aquele atributo de outrora que caracterizava os partidos e movimentos sociais vanguardistas e de esquerda (anarquistas, socialistas, comunistas), passou agora a caracterizar os movimentos de direita e extrema direita ultraliberais.

As contradições da sociedade capitalista passaram a ser cada vez mais evidentes - com uns poucos concentrando a maior parte do capital ao tempo que uma esmagadora maioria passou a sofrer as consequências da crise, isto é, o desemprego, a perda de direitos trabalhistas e sociais e a rápida privatização dos espaços públicos. Nesta conjuntura adversa, os deserdados do sistema em geral, e os trabalhadores em particular, são seduzidos por grupos que apontam para saídas dramáticas, criando uma atmosfera ideal para a eclosão de movimentos nacionalistas e conservadores, que pregam a subjugação e até mesmo a eliminação de determinados extratos sociais: os estrangeiros, os imigrantes, as minorias 
étnicas, raciais, sexuais (lésbicas, gays, bissexuais, transexuais etc.) e religiosas.

Nesse controvertido contexto, começaram a aparecer os arautos da "purificação" nacional, que consideram os coletivos supracitados responsáveis pela degradação econômica, política, social e moral dos países capitalistas centrais e periféricos, bem como dos seus respectivos sistemas democráticos liberais. A solução para os setores mais reacionários e ultraliberais passaria por tentar organizar a sociedade e defender o modelo de família tradicional, com base em um ajustamento ou exclusão dos indivíduos desses coletivos que eles consideram indesejáveis, portanto, elimináveis.

\section{4ª Glosa crítica. O movimento Escola sem Partido segue as orientações do fundamentalismo econômico e da ideologia ultraliberal.}

Tendo como principal fundamento a defesa de valores, princípios e direitos humanos legados das Revoluções Burguesas do século XVIII e XIX, a crise da democracia liberal é decorrente da atual crise econômica capitalista, com todas as consequências destrutivas imaginadas: monopolização dos poderes econômicos, políticos e culturais nas mãos dos EUA e dos organismos políticos e financeiros internacionais intergovernamentais (Fundo Monetário Internacional-FMI, Organização para a Cooperação e Desenvolvimento Econômico-OCDE, Banco Central Europeu-BCE, Banco Mundial-BM, União Europeia-EU, Acordo Geral de Tarifas e Comércio-GATT, Organização do Tratado do Atlântico Norte-OTAN), para defender os interesses de um único modelo societário possível (formação social capitalista), sempre sob os desígnios do capital internacional.

Como a crise do modo de produção do capital foi se agravando, resultando diretamente no fim da experiência do Estado do Bem-estar Social, a ideologia ultraliberal se fortaleceu em todo o mundo, sempre no sentido de diminuir e esvaziar o caráter público do Estado capitalista e subtrair direitos trabalhistas e sociais. Ocorreu, assim, um processo de reestruturação regressiva em escala planetária, comandada em diversos países por partidos 
políticos de extrema direita, orientados por uma ideologia que passou a ser dominante, a ideologia ultraliberal.

As premissas que orientam as ações do movimento Escola sem Partido derivam da adesão indisfarçada de seus integrantes aos fundamentos do mercado, no qual se percebe a defesa do individualismo, da meritocracia e da não-intervenção do Estado nas relações econômicas e sociais. É importante frisar, nesse particular, que essa defesa da não - intervenção estatal nas relações sociais se conjuga como sendo um preceito central e útil ao sistema do capital. Nesta perspectiva, existe a impressão de que tanto a intervenção econômica do Estado quanto a social ferem a liberdade individual advinda da tradição liberal. Por outro lado, os movimentos e grupos sociais que questionam o status quo, geralmente simpatizantes a teorias vinculadas aos campos políticos e culturais marxistas, como por exemplo o movimento feminista, movimentos identitários, organizações de esquerda e os sindicatos progressistas, são transformados nos principais adversários a serem combatidos na perspectiva do movimento Escola sem Partido.

\section{$5^{a}$. Glosa crítica. Além do fundamentalismo econômico, o movimento Escola sem Partido também articula as suas açōes ao fundamentalismo religioso.}

O contexto da profunda crise do capital sedimenta uma articulação perversa entre o fundamentalismo de mercado e o fundamentalismo religioso, pois os direitos sociais e trabalhistas são colocados em uma mesma malha discursiva e apresentados à sociedade como privilégios injustificados, como desvios da ordem natural das coisas. A construção deste discurso criminaliza a liberdade de expressão, o direito ao próprio corpo, as manifestações culturais ou as políticas de distribuição de renda e acesso às universidades; é inútil procurar os padrões mínimos que justificam e aproximam as críticas dos idealizadores do Escola sem Partido em áreas tão diferentes. O campo dos costumes é associado vulgarmente ao das políticas públicas de inclusão social e da afirmação dos direitos subjetivos. Todas as transformações sociais originadas dos processos de democratização e da 
produção científica são interpretadas como suspeitas, desde que afrontem os interesses do capital e do reacionarismo religioso.

Ainda que esse tipo de atitude já provoque assombro, há ainda uma importante variável de natureza econômica vinculada à religião e que por estes motivos, precisa ser ressaltada. Como parte das classes médias assimila e defende os preceitos ideológicos do capital, a tendência é que esses segmentos responsabilizem os setores menos favorecidos socialmente pelas suas próprias dificuldades de ascensão social ou mesmo de manutenção do seu status momentâneo, uma vez que subsistem fortes preconceitos de classe. Ao se defrontarem com algum tipo de mobilidade social e econômica de outros segmentos diferentes dos seus (as diversas frações de classe que caracterizam a sociedade brasileira), ainda que seja insuficiente no sentido de alteração do padrão de organização da riqueza e do poder político existente, as classes médias não hesitam em se posicionar do lado dos opressores. Observa-se que quando se trata de defender interesses econômicos, existe uma espécie de vale tudo, mesmo que com isso se atente contra princípios fundamentais do cristianismo como, por exemplo, o amor ao próximo, a solidariedade, a partilha, a humildade e o perdão.

\section{Glosa crítica. A Escola sem Partido sente aversão à produção e divulgação do conhecimento científico.}

Isto que faz com que o movimento estabeleça alianças com os setores mais à direita da igreja católica e das igrejas neopentecostais, que compartilham entre si uma percepção da realidade alicerçada em princípios éticos e morais orientados pela crença religiosa, em que se destaca uma organização social de natureza fundamentalista, de corte patriarcal, homofóbico, autoritário, anticientífico e eurocêntrico. É em razão desta associação com tais igrejas que o movimento Escola sem Partido prioriza o ataque ao movimento feminista - e ao direito ao corpo -, ao público LGBT (e por derivação, as discussões sobre a sexualidade assumem destaque primordial em suas estratégias de mobilização), às religiões de matriz africana e às diversidades de modo geral, considerados "desvios" de 
algum tipo de cultura padrão. Essas religiões cristãs têm manifestado a sua adesão ao movimento "pró-vida" (são contra o aborto), mas também são contrárias a pautas identitárias e ao que elas denominam de marxismo cultural.

As perseguições aos professores guardam então estreita ligação com esta aversão à produção e socialização dos conhecimentos valorizados socialmente e reconhecidos como uma construção cultural e científica da humanidade, considerando as funções que estes profissionais desempenham nos processos pedagógicos, preservando e estimulando o saber racional de maneira ampla, ao mesmo tempo em que dialogam com as culturas próprias da própria sociedade em conflito. De qualquer modo, essa postura se opõe inteiramente aos ditames éticos e culturais presentes nos conceitos difundidos pelo fundamentalismo religioso, que por sua natureza, não admite questionamentos quanto aos seus postulados civilizatórios, bem como não aceitam a existência de arranjos sociais, familiares e culturais que estejam em desacordo com os dogmas religiosos mais conservadores.

$\mathrm{Na}$ realidade, esta postura das instituições religiosas demarca as relações entre religiosidade e ciência, que estão na base dos conflitos entre a burguesia e as instituições feudais, dentre estas e a igreja católica. Mas é interessante notar que esta coibição da reflexão e busca de alternativas contra hegemônicas ao sistema de capital vigente, que se apropria dos espaços educacionais para transmissão e consolidação dos seus valores de mercado (garantindo, dessa maneira, a reprodução dos mecanismos de dominação por meio das relações sociais de educação), é não apenas tolerado, mas defendido pelos ideólogos da ESP, o que demonstra a falsidade de que o mesmo representa um movimento neutro do ponto de vista político e ideológico, o que de saída, já contrariaria qualquer preceito lógico de organização social e cultural da humanidade. Reproduz-se, no caso em tela, uma associação entre as instituições burguesas e as religiosas cristãs com o objetivo de silenciar os críticos de ambas as áreas, - a economia e a religião -, algo comum na história das civilizações, quando a 
religião se põe a serviço das classes dominantes e do seu sistema econômico (e vice-versa).

\section{$7^{\text {a }}$. Glosa crítica. O movimento manifesta ser contrário à existência de minorias, justo num país onde as minorias somadas constituem uma autêntica maioria.}

Apesar da expressão minorias, acreditamos que a censura e perseguição reacionária do movimento se refira de fato a uma maioria da sociedade, composta por mulheres, negros, público LGBT, praticantes de religiosidades de matriz africana, dentre outros, que desafiam os conceitos eurocêntricos cristãos e os valores patriarcais à proporção que estes sintetizam um padrão de comportamento e cultura de verniz autoritário, que não aceita ser desafiado em sua lógica de organização, resultando que os segmentos destoantes acabam sendo criminalizados de modo implacável. Conforme expressamos anteriormente, é no campo dos costumes que a ação do ESP concentra toda a sua força, logrando a obtenção de maciço apoio de grande parte da sociedade, que enxerga a realidade unicamente conforme este prisma.

As acusações, por parte dos ideólogos do movimento, de que existem movimentos de desconstrução da "família tradicional", de deturpação e corrupção da infância através da sexualização precoce e do estímulo às práticas homossexuais, envolvem aspectos sociológicos, culturais e políticos que não podem ser menosprezados. Como sabido, essas acusações que movimentam grande parte das ações do movimento não faziam parte dos objetivos iniciais dos seus idealizadores, que focavam principalmente no combate ao denominado marxismo cultural. Apenas quando perceberam a importância simbólica de inclusão desta pauta de cunho moralista para a efetiva ampliação da sua base de apoio, principalmente entre o público neopentecostal, é que esta questão passou a ser uma das bandeiras centrais da Escola sem Partido. Os movimentos feministas e o LGBT são os alvos preferenciais da campanha de criminalização levada a efeito pelo movimento, mas as crianças, consideradas na forma da lei sujeitos de direito, 
são igualmente vítimas da ação repressiva do movimento, que se articula com os veículos de imprensa, o aparato judicial e a classe política mais reacionária para organizar um conjunto de medidas de intimidação e perseguição a essa parcela da sociedade.

Com esses propósitos repressivos, a utilização dos fake news é recorrente: a invenção da "cartilha gay", "da mamadeira erótica", "da ideologia de gênero" foram os carros-chefes da ampla campanha midiática que descontruiu os processos democráticos de elaboração dos planos de educação em todo o país, bem como estimulou a proposição dos inúmeros projetos de lei que levam o nome do movimento Escola sem Partido, onde os educadores e a comunidade acadêmica pouco puderam fazer contra a avalanche de deturpações e mentiras que tomou conta das audiências públicas e sessões legislativas nas instâncias parlamentares brasileiras.

A defesa do direito ao aborto (encampado por parte do movimento feminista) e da união civil de pessoas do mesmo sexo (liderado pelo público LGBT) provocaram verdadeiras explosões de fúria dos segmentos fundamentalistas, que recorreram a todos os meios políticos e jurídicos disponíveis contra tais bandeiras (em nome da família tradicional, da vida e da moral cristã, conforme as declarações públicas, documentos, manifestações e as palavras de ordem que estes bradavam). Nesses embates, parte importante da opinião pública se posicionou ao lado do movimento ESP.

\section{8a. Glosa crítica. Os educadores do movimento Escola sem Partido não sabem nada de educação.}

Cada vez que ouvimos os referentes intelectuais do movimento (geralmente juízes, militares, políticos, pastores evangélicos, pretensos filósofos e indivíduos autoproclamados "cidadãos de bem"), pairam algumasdúvidas: Será que eles entendem algo de educação? Conhecem a natureza do trabalho pedagógico? Compreendem a importância que o conhecimento científico tem para os avanços da humanidade? A proposta 
do movimento não tem mesmo partido? Quem são os autênticos doutrinadores nesta história?

De antemão, precisamos partir do pressuposto de que as críticas do movimento são direcionadas às instituições educativas burguesas - as verdadeiras responsáveis pelo fracasso educacional brasileiro. Portanto, se o movimento tem críticas a serem feitas, elas precisariam focar no fracasso da educação brasileira e da escola capitalista liberal, que tem se demonstrado incapaz de cumprir a sua função social. Tomemos como exemplo as universidades públicas federais. Se dentre seus professores não há dúvidas de que a universidade brasileira é conservadora, na percepção dos defensores do movimento Escola sem Partido as instituições universitárias estão cheias de professores... comunistas!

Em termos pedagógicos, podemos afirmar que a proposta do Escola sem Partido visa aprofundar a perspectiva neotecnicista que orienta a formulação das políticas públicas educacionais dos últimos tempos. Trata-se de uma proposta educacional baseada na Pedagogia das competências, na perspectiva do aprender a aprender. Nesta perspectiva, se busca substituir o conceito de qualificação pelo de competência, e com isso o ensino centrado nas disciplinas de conhecimento abre espaço para o ensino por competências. No dizer de Saviani (2012, p. 169),

\footnotetext{
Estamos, pois, diante de um neotecnicismo: o controle decisivo desloca-se do processo para os resultados. É pela avaliação dos resultados que se buscará garantir a eficiência e produtividade. E a avaliação converte-se no papel principal a ser exercido pelo Estado, seja mediante, pela criação das agências reguladoras, seja diretamente, como vem ocorrendo no caso da educação, com a criação de sistemas nacionais de avaliação incumbidos de avaliar os alunos, as escolas, os professores e, a partir dos resultados obtidos, condicionar a distribuição de verbas e a alocação de recursos conforme os critérios de eficiência e produtividade.
}

Nas sociedades divididas em classes antagônicas, os resultados da produção material e não-material sempre beneficiam as classes dominantes. Segundo Saviani e Duarte (2015, p. 21),

Mas no longo período da história social, marcado pela divisão das sociedades em classes antagônicas, as relações de produção 
existentes entre as classes fundamentais caracterizam-se pela divisão social do trabalho, acarretando que a objetivação do ser humano e a apropriação dos resultados dessa objetivação ocorressem sob formas que impediram que a totalidade da riqueza material e não material fosse posta a serviço da realização e do desenvolvimento da totalidade dos seres humanos.

No que diz respeito a matriz curricular das áreas Humanas e Sociais, o cruzamento dos interesses entre fundamentalismo econômico e religioso é também claramente percebido, com destaque para a censura às teorias marxistas e ao conjunto de conhecimentos das áreas de História, Sociologia, Filosofia, Política, Antropologia, Educação etc., se prestando a dois propósitos fundamentais:

1) Cerceamento das referências centrais que fazem a crítica ao modo de produção capitalista e às ideologias neoliberal e ultraliberal, dada a necessidade de manutenção e ampliação da exploração do trabalho e da acumulação intrínseca ao mercado, com consequências importantes para a elaboração de justificativas de desconstrução dos direitos trabalhistas e sociais e aos ataques aos sindicatos organizados em torno da valorização e defesa do trabalho;

2) Questionamento da racionalidade e da ciência, pois eles são incompatíveis com os dogmas religiosos advindos das Igrejas Pentecostais (evangélica) e da Renovação Carismática (católica) -, justamente as instituições religiosas mais conservadoras, autoritárias e reacionárias, quando se trata das questões relacionadas aos conhecimentos historicamente legitimados pela humanidade e que são discutidos nas instituições educacionais.

\section{9a. Glosa crítica. A Pedagogia Histórico-crítica é uma perspectiva teórica} capaz de resolver as históricas mazelas educacionais que caracterizam 0 Brasil na atualidade.

A Pedagogia Histórico-crítica surgiu no início da década de 1980 , como resposta às necessidades dos educadores brasileiros de tentar superar os estreitos limites das pedagogias não-críticas (escola tradicional, escola nova e tecnicismo), mas também das pedagogias crítico-reprodutivistas (expressas nas teorias da escola como aparelho ideológico do Estado de Louis Althusser, a proposta da escola dualista de Baudelot e Establet, e a 
teoria da reprodução de Bourdieu e Passeron). Para esta teoria, é evidente que as contradições que marcam a organização social baseada na propriedade privada são orgânicas e não apenas estruturais. "Portanto, para resolvê-las, é necessário alterar as próprias relações sociais que as determinam. E só a partir daí será possível resolver também os graves problemas educacionais que vêm afligindo os educadores e toda a população brasileira" (SAVIANI, 2013, p. XVI).

Nesta perspectiva, a educação (ou prática educativa) é concebida como uma modalidade da prática social, essencial para que os homens possam construir a sua segunda natureza: o mundo do humano, o mundo da cultura. Para tanto, o saber objetivo produzido historicamente pela sociedade é considerado patrimônio da humanidade. Com isso, a tarefa histórica que se propõe a Pedagogia Histórico-crítica em relação à educação escolar implica:

a) Identificação das formas mais desenvolvidas em que se expressa o saber objetivo produzido historicamente, reconhecendo as condições de sua produção, compreendendo as suas principais manifestações, bem como as tendências atuais de sua transformação.

b) Conversão do saber objetivo em saber escolar, de modo que se torne assimilável pelos alunos no espaço e tempos escolares.

c) Provimento dos meios necessários para que os alunos não apenas assimilem o saber objetivo enquanto resultado, mas apreendam o processo de sua produção, bem como as tendências de sua transformação (SAVIANI, 2013, p. 08-09).

O desafio da Pedagogia Histórico-crítica é, portanto, reconhecer as formas mais desenvolvidas de expressão do saber humano, a sua conversão em saber escolar, e o provimento dos meios necessários para que os alunos, além de assimilarem o saber objetivo enquanto resultado - possam apreender também o processo de sua produção. Somente assim seremos capazes de superar as contradições que caracterizam as sociedades divididas em classes. Gramsci (2004) nos lembra que:

O homem conhece objetivamente na medida em que 0 conhecimento é real para todo o gênero humano historicamente unificado em um sistema cultural unitário; mas esse processo de unificação histórica ocorre com 0 desaparecimento das contradições internas que dilaceram a sociedade humana, 
contradições que são a condição da formação dos grupos e do nascimento das ideologias não universal-concretas, mas que envelhecem imediatamente, por causa da origem prática de sua substância. Há, portanto, uma luta pela objetividade (para libertar-se das ideologias parciais e falazes) e esta luta é a própria luta pela unificação cultural do gênero humano (GRAMSCl, 2004, p. 134).

Sabe-se que no Brasil, o saber escolar sempre foi hegemonizado pela burguesia. Ancorada na perspectiva cultural histórico-proletária, a Pedagogia Histórico-crítica busca apropriar-se do saber burguês, para assim poder the inverter o sinal, de modo que desarticulando-o dos interesses burgueses, possam ser colocados a favor da classe como um todo. Para o formulador desta proposta, "... esse saber, que, de si, não é burguês, serve, no entanto, aos interesses burgueses, uma vez que a burguesia dele se apropria, colocando-o a seu serviço e o sonega das classes trabalhadoras". Neste sentido, passa a ser fundamental a luta contra essa sonegação, "...uma vez que é pela apropriação do saber escolar por parte dos trabalhadores que serão retirados desse saber seus caracteres burgueses e se lhe imprimirão os caracteres proletários" (SAVIANI, 2013, p. 48).

Para a Pedagogia Histórico-crítica, nas sociedades divididas em classes (como é o caso da sociedade brasileira), a educação é um ato político, tanto quanto a defesa que a extrema direita faz da educação, como se ela fosse isenta de influência políticas - denotando desta forma o interesse de colocar a educação a serviço das classes dominantes. No entendimento de Saviani,

...agir como se a educação fosse isenta de influência política é uma forma eficiente de colocá-la a serviço dos interesses dominantes. E é esse o sentido do programa "escola sem partido" que visa, explicitamente, subtrair a escola do que seus adeptos entendem como "ideologias de esquerda", colocando-a sob a influência da ideologia e dos partidos da direita, portanto, a serviço dos interesses dominantes. Ao proclamar a neutralidade da educação em relação à política, o objetivo a atingir é o de estimular o idealismo dos professores fazendo-os acreditar na autonomia da educação em relação à política, o que os fará atingir o resultado inverso ao que estão buscando: em lugar de, como acreditam, estar preparando seus alunos para atuar de forma autônoma e crítica na sociedade, estarão formando para ajustá-los melhor à ordem existente e aceitar as condições de dominação às quais estão submetidos. Eis por que a proposta da escola sem partido se origina de partidos situados à direita do espectro político (SAVIANI, 2018, p. 784), 
Desta feita, é evidente que a própria denominação do movimento (Escola sem Partido), camufla o seu alinhamento ideológico aos partidos conservadores e reacionários de extrema direita, como modo e estratégia de manter vigentes as desigualdades sociais que caracterizam historicamente a sociedade brasileira.

\section{Glosa crítica. A superação dos problemas da educação brasileira deve passar pela superação da sociedade capitalista, na perspectiva da construção de uma sociedade mais igualitária e emancipada.}

Diante das considerações até agora supracitadas, fica evidente que a educação isoladamente não será capaz de resolver todos os problemas sociais que existentes no Brasil. Isto não quer dizer tampouco que deixemos de valorizar o seu importante papel nas sociedades classistas. Mészáros (2015) nos lembra que não há como fugir do círculo vicioso das determinações inerentemente antagônicas do capital, que colocam em xeque-mate, inclusive, a própria sobrevivência da humanidade, sem alterar radicalmente "...a nossa modalidade de controle sociometabólico ao erradicar completamente o capital do processo de reprodução social" (MÉSZÁROS, 2015, p. 95 - grifos do autor).

Neste sentido, defendemos a hipótese de que os problemas educacionais das sociedades de classes só serão superados com o fim do modo de produção capitalista por uma organização societária e econômica que torne possível a realização plena das capacidades humanas. O desafio histórico da emancipação humana em termos universais coloca no horizonte a necessidade da construção de um novo mundo, mais fraterno e solidário, que supere as contradições geradas pelo capitalismo, que necessariamente implica no desaparecimento do atual modelo econômico opressivo e excludente. Ainda que a configuração desta nova realidade não seja algo concreto, restam, portanto, ações pontuais junto aos movimentos sociais e políticos em defensa de uma democracia substantiva e de uma sociedade mais justa. 


\section{CONSIDERAÇÕES FINAIS}

De modo geral, consideramos o Escola sem Partido um movimento autoritário, articulado com o movimento fascista internacional. Suas articulações, tanto internas quanto externas, representam o violento esforço do sistema do capital em manter o seu processo de acumulação e concentração da riqueza, ainda que ele precise se utilizar de recursos que minam o Estado democrático de Direito liberal e das limitadas conquistas possibilitadas pela ampliação dos espaços de democratização formal.

No Brasil, esse movimento reacionário e neofascista uniu-se à outras organizações sociais importantes, como as instituições religiosas cristãs. Incorporando as pautas dos costumes, o Escola sem Partido logrou a ampliação e consolidação de uma significativa base de apoio popular, possibilitando eleger representações políticas, especialmente parlamentares, para a apresentação e defesa das suas pautas nos espaços formais de construção das políticas públicas educacionais.

Desse modo, a influência do movimento ESP se reflete em uma disputa ideológica nas matrizes curriculares dos sistemas educacionais, na seleção dos livros didáticos, na aquisição dos suportes paradidáticos e tecnológicos à docência e ao processo de ensino/aprendizagem, na escolha dos projetos a serem implementados nas escolas, na expansão das instituições educacionais de natureza militar e religiosa etc. naturalizando uma reorientação de viés autoritário no campo educacional em detrimento de um modelo educacional mais democrático. Para os defensores do movimento ESP, os objetivos autoritários, obscurantistas e privatistas caminham juntos, sem maiores contradições internas, pois é justamente a unificação destes interesses que asseguram capilaridade e força ao movimento.

Consideramos que a desconstrução das proposituras do Escola sem Partido só será possivel se os movimentos defensores da educação pública e da democracia passarem a adotar a estratégia da resistência ativa. O professor Saviani nos lembra de que a estratégia da resistência ativa implica dois requisitos: 
a) ela precisa ser coletiva. Para o autor, a resistência individual não tem força para enfrentar ao domínio imposto por um governo ilegítimo e antipopular;

b) ela precisa ser propositiva, para que seja capaz de demarcar alternativas que conduzam à derrocada definitiva das propostas da extrema direita. "Podemos ver que esses dois requisitos correspondem ao duplo papel da educação: de resistência e de transformação" (SAVIANI, 2018, p. 785).

Pelo exposto, entendemos que a elaboração de um modelo de educação emancipatório precisa reestabelecer os princípios de sociabilidade, cooperação e fraternidade humanas, pondo fim às construções subjetivistas de caráter individualista e que excluem amplos segmentos da população das conquistas sociais e dos direitos já suficientemente institucionalizados no ordenamento legal, ora ameaçados pelo crescimento dos movimentos políticos e educacionais de cunho fascista, do qual a Escola sem Partido é legítima representante. Esta é a tarefa das gerações atuais, que precisam demonstrar a capacidade de organização e resistência exigida pelos desafios postos na atualidade.

\section{REFERÊNCIAS}

CASTELLS, M. Ruptura: a crise da democracia liberal. Rio de Janeiro: Zahar, 2018.

EVANGELISTA, J. E. Crise do marxismo e irracionalismo pós-moderno. São Paulo: Cortez Editora, 1997.

FRIGOTTO, G.; PENNA, F.; QUEIROZ, F. (org.) Educação democrática: antídoto ao Escola sem Partido. Rio de Janeiro: UERJ/LPP, 2018.

FRIGOTTO, G. (org.) Escola "sem" Partido. Esfinge que ameaça a educação e a sociedade brasileira. $2^{a}$. reimpressão. Rio de Janeiro: UERJ/LPP, 2017.

GALEANO, E. Las venas abiertas de América Latina. 8a. ed. revisada y ampliada. Montevideo: Ediciones del Chanchito, 2006.

GRAMSCl, A. Cadernos do cárcere, volume 1 (Introdução ao estudo da filosofia de Benedetto Croce). $3^{a}$. ed. Rio de Janeiro: Civilização Brasileira, 2004.

HERMIDA, J. F.; LIRA, J. de S. Quando fundamentalismo religioso e mercado se encontram: as bases históricas, econômicas e políticas da escola sem partido. Roteiro, v. 45, p. 1-32, 9 jun. 2020. 
HERMIDA, J. F.; LIRA, J. de S. O Programa Escola Livre em Alagoas, a crise de acumulação do capital e o fortalecimento da direita política brasileira.

Revista Exitus, v. $8 n^{\circ} 1$, p. 141-170. Jan./Abr. 2018.

HERMIDA, J. F. e LIRA, J. de S. Políticas educacionais em tempos de golpe: entrevista com Dermeval Saviani. Revista Educação e Sociedade. Campinas, v. 39, no. 144, p.779-794, jul.-set. 2018b.

LEVITSKY, S. e ZIBLATT, D. Como as democracias morrem. Rio de Janeiro: Zahar, 2018.

MARX, K. O 18 de Brumário de Luís Bonaparte. São Paulo: Boitempo, 2011.

MÉSZÁROS, I. A montanha que devemos conquistar, São Paulo: Boitempo, 2015.

NICOLAU, J. Prefácio. In: LEVITSKY, S. e ZIBLATT, D. Como as democracias morrem. Rio de Janeiro: Zahar, 2018.

REVISTA VEJA. Em mensagem, novo ministro da Educação fala sobre suas prioridades. In: <https://veja.abril.com.br/brasil/em-mensagem-novo-ministroda-educacao-fala-sobre-suas-prioridades/> Acesso em: 29/07/2020.

SAVIANI, D. Entrevista. In: HERMIDA, J. F. e LIRA, J. de S. Políticas educacionais em tempos de golpe: entrevista com Dermeval Saviani. Revista Educação e Sociedade. Campinas, v. 39, nº 144, p.779-794, jul.-set. 2018.

SAVIANI, D. e DUARTE. N. Pedagogia Hustórico-crítica e luta de classes na educação escolar. Campinas: Autores Associados, 2015.

SAVIANI, D. Pedagogia Histórico-crítica: primeiras aproximações. $11^{a}$. ed. ampliada e revisada. Campinas: Autores Associados, 2013.

SAVIANI, D. A pedagogia no Brasil: história e teoria. $2^{a}$. ed. Campinas: Autores Associados, 2012.

UOL. Weintraub deixa o governo: seis polêmicas que marcaram a gestão no Ministério da Educação. In: <https://noticias.uol.com.br/ultimasnoticias/bbc/2020/06/18/weintraub-deixa-o-governo-seis-polemicas-quemarcaram-a-gestao-no-ministerio-da-educacao.htm> Acesso em: 29/07/2020.

Recebido em: 11 de janeiro de 2021. Aprovado em: 31 de março de 2021. Publicado em: 09 de abril de 2021. 